\title{
A quantitative study of the influence of fixation on immunoperoxidase staining of rectal mucosal plasma cells
}

\author{
JUAN PIRIS AND ND THOMAS
}

From the University of Oxford, Department of Pathology, John Radcliffe Hospital, Oxford, UK

SUMMARY A quantitative morphometric study of the immunoglobulin-containing plasma cells in rectal biopsies from nine patients with ulcerative colitis and three patients with the irritable colon syndrome is presented. The results show that fixation of the biopsy specimens with formol-sublimate, a mercuric fixative, resulted in better staining with the immunoperoxidase method and that, by comparison with formol saline, higher cell counts were always obtained.

It has been known for some time that the results obtained with the immunoperoxidase method are dependent to some extent on the type of fixative used before processing the biopsy specimens. ${ }^{1}$ Our preliminary results (Piris and Thomas, unpublished observation), carried out before the report by Bosman et al. ${ }^{1}$ was published, coincided with theirs in that we also believe that sublimate-formaldehyde is superior to ordinary formalin and Zenker's fluid fixative. We are concerned that these differences in the consistency with which adequate positive results are obtained, the intensity of the specific peroxidase reaction, and the undesirable background non-specific staining may result in a quantitative difference brought about by the inability to detect weakly stained positive cells in a not too clear background.

The present paper deals with the results of a morphometric quantitative study of mucosal immunocytes in rectal biopsy specimens, fixed with either formol saline or sublimate-formaldehyde, and stained with an immunoperoxidase method.

\section{Material and methods}

Two biopsy specimens from adjacent areas of the anterior rectal wall were obtained from nine patients with ulcerative colitis who were in remission. The specimens were randomly fixed in either formol saline or sublimate-formaldehyde (a 9:1 mixture by volume of saturated mercuric chloride and formalin).

Three more biopsy specimens, obtained from three patients with the irritable colon syndrome,

Received for publication 25 October 1979 were immediately bisected, and each half was fixed in one of the two fixatives. After routine processing $4 \mu$ thick sections were cut and stained with haematoxylin and eosin. All specimens included the muscularis mucosae and were free from ulceration. There was no obvious subjective difference in the degree of inflammatory infiltration in the lamina propria of the corresponding two halves of each specimen.

The specimens were then stained with the indirect ('sandwich') peroxidase method of Taylor and Burns. ${ }^{2}$ After dewaxing, ali sections, whether fixed in formalin or sublimate, were treated with iodine and hypochloride to remove the mercury and then washed well in water; the endogenous peroxidase activity is blocked with a fresh solution of $0.5 \%$ hydrogen peroxidase in methanol for 30 minutes; after washing in phosphate buffered saline (PBS) the sections are exposed to a 1 in 5 solution of normal swine serum for 10 minutes to reduce the nonspecific background staining. The first specific antibody, a mixture of rabbit anti-human $\kappa$ (kappa) and rabbit anti-human $\lambda$ (lambda) light chain antisera purchased from DAKO-Immunoglobulins Ltd is then used at a dilution of $1: 20$ in $1: 20$ normal swine serum in PBS for 30 minutes. This is followed, after a wash in PBS, by incubation with peroxidase conjugated swine anti-rabbit IgG serum at 1:20. The peroxidase activity is demonstrated by adding the substrate, diaminobenzidine tetrahydrochloride and $\mathrm{H}_{2} \mathrm{O}_{2}$, which results in a visible brown precipitate being deposited at the site where the peroxidase is available. The slides were counterstained with Harris' haematoxylin and mounted. Two control sections were included; in one of them the first anti- 
body (rabbit anti-human $\lambda$ and $\kappa$ light chains) was omitted. In the other, the second antibody (swine anti-rabbit IgG) was omitted. Both control sections show no staining of plasma cells.

\section{QUANTITATIVE PROCEDURE}

The method was similar to that described by Skinner and Whitehead. ${ }^{3}$ A Leitz microprojector fitted with a $\times 40$ lens was used to project the image on to a grid in which points were marked $2 \mathrm{~cm}$ apart at the corners of equilateral triangles. By means of the mechanical stage of the microscope, the histological sections were screened, and the number of points falling on the lamina propria, as well as the number of positive staining plasma cells, were recorded. This was done ensuring that the fields counted included all possible areas of the mucosa, that is, under the surface epithelium, in the mid-zone, and at the base of the mucosa above the muscularis mucosae.

By means of a summation average graph, ${ }^{4}$ it was concluded that, at the chosen magnification, the area of lamina propria examined by counting one thousand points constituted a representative sample of the whole biopsy specimen since the ratio plasma

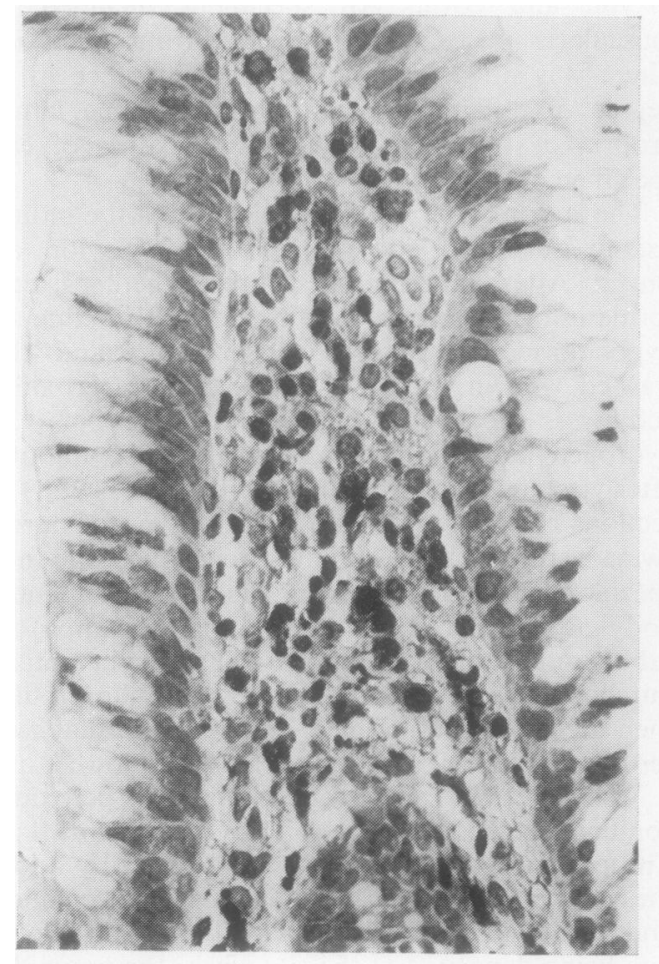

(a) cells: points in the lamina propria was stable in all cases, after about 700 points (Fig. 1).

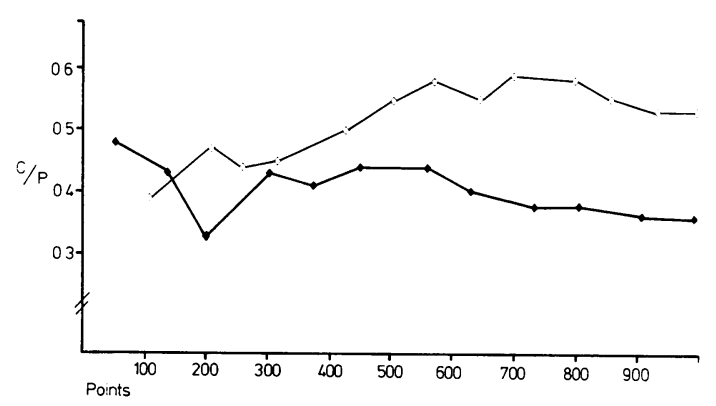

Fig. 1 Summation average graph plotted for the ratio of plasma cells to points in lamina propria $(C / P)$. After counting 600 points the mean varies very little.

\section{Results}

The appearance of the haematoxylin and eosin stained slides from the specimens fixed in sublimate is better than that of the ones fixed in formol saline;

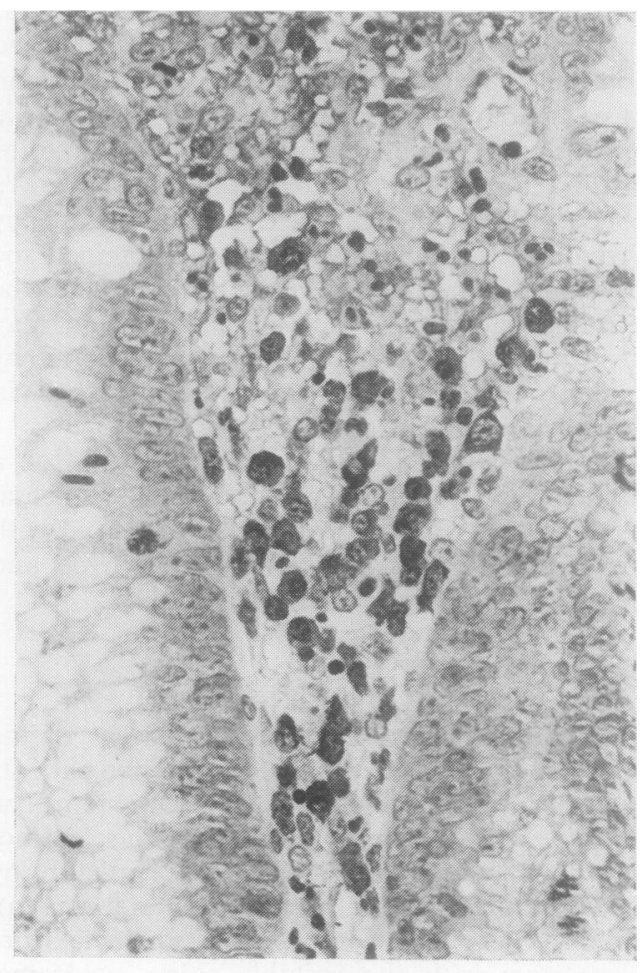

(b)

Fig. 2 Case 7. Rectal biopsy specimen fixed with (a) formol saline and (b) formol sublimate and stained with an immunoperoxidase method for the demonstration of immunoglobulin-containing plasma cells. $\times 395$ 


\begin{tabular}{|c|c|c|c|c|c|}
\hline Case & Sex & Age & Diagnosis & $C / P(F S)$ & $C / P(F H g)$ \\
\hline 1 & $\mathbf{M}$ & 56 & ICS & 0.15 & 0.62 \\
\hline 2 & $\mathbf{F}$ & 47 & ICS & $0 \cdot 16$ & 0.53 \\
\hline 3 & $\mathbf{M}$ & 55 & UC & 0.28 & $0 \cdot 34$ \\
\hline 4 & $\mathbf{F}$ & 31 & UC & 0.26 & 0.34 \\
\hline 5 & $\mathbf{F}$ & 50 & UC & 0.44 & 0.95 \\
\hline 6 & $\mathbf{F}$ & 39 & UC & 0.61 & 1.01 \\
\hline 7 & $\mathbf{M}$ & 31 & UC & 0.56 & 0.61 \\
\hline 8 & $\mathbf{M}$ & 69 & UC & 0.57 & 0.72 \\
\hline 9 & $\mathbf{F}$ & 30 & UC & $0 \cdot 13$ & 0.29 \\
\hline 10 & $\mathbf{M}$ & 70 & UC & 0.23 & 0.55 \\
\hline 11 & $\mathbf{M}$ & 36 & UC & $0 \cdot 16$ & 0.52 \\
\hline 12 & M & 29 & ICS & $0 \cdot 15$ & $0 \cdot 33$ \\
\hline
\end{tabular}

$\mathrm{C} / \mathrm{P}=$ ratio of plasma cells to points; $\mathrm{FS}=$ formol saline; $\mathrm{FHg}=$ formol sublimate; $\mathrm{ICS}=$ irritable colon syndrome; UC $=$ ulcerative colitis. Student's $t$ test for paired samples: $t=5.46, \mathrm{P}<0.001$.

in particular, the nuclear detail is enhanced. With the peroxidase method, the intensity of the reaction appears much greater, and this allows for better definition of the cell contours. Also, the staining of connective tissue fibres and ground substance is less marked (Fig. 2). As expected after blocking endogenous peroxidase the granules of polymorphonuclear neutrophils and eosinophils were not stained in the sections fixed with either fixative. The use of iodine and hypochloride in formalin fixed sections made no difference to the staining results when compared with similar specimens also fixed in formalin but not treated with these compounds.

The quantitative results of the 12 cases are summarised in the Table, in which the ratios of plasma cells to points in the lamina propria are given in the corresponding columns according to the fixative used. In all cases more immunoglobulin-containing plasma cells were seen in the specimens fixed in formol sublimate. The degree of difference was not constant, being marginal in some cases whereas in others it was threefold or fourfold.

The difference can be analysed statistically by means of Student's $t$ test for paired observations, which gives a value of $t$ of $5 \cdot 46$, highly significant at the 0.001 level.

\section{Discussion}

Because of the undoubted role of immunological mechanisms in some forms of gastrointestinal disease, the local cellular infiltration by immunoglobulinproducing plasma cells has recently been the subject of several studies. ${ }^{356}$ Many of these studies are based on immunofluorescent methods, but it is clear that the possibility of using routinely fixed paraffinembedded tissue sections represents an enormous advantage. The immunoperoxidase technique provides a means for the study of immunocytes, and of many other types of cells containing antigenic material against which an antibody can be raised such as hormones; the biopsy specimens can be stored permanently and studied at a convenient time; also the final preparation is stable and does not fade with time, thus obviating the need for immediate staining and photography. Although formalin-fixed material is satisfactory substrate for this immunohistochemical method, it is our belief that the final result, and the consistency of the reaction, are much improved by the use of the sublimate-formaldehyde. This fixative does not affect the staining characteristics of the tissues by the routine methods such as haematoxylin and eosin or periodic acid Schiff, and the number of cells stained by non-immunological methods-such as carbol chromotope for eosinophils -is no different from that obtained when formol saline is used as a fixative. ${ }^{\text {? }}$

Formol sublimate contains mercuric chloride, and reasonable precautions should be taken to avoid inhaling dust when preparing the mercuric chloride solution and to prevent direct contact with the skin. Because of its corrosive properties metal instruments and containers with metal caps should not be used. Excessive fixation of tissues should be avoided to prevent undue hardness.

We thank Dr S C Truelove for allowing us to study his patients and $\mathrm{Dr} \mathbf{P}$ Willoughby and $\mathrm{Dr} \mathbf{M}$ Hayworth for taking the biopsies. We are also grateful to Mrs Sue Canning and Mr Roy Holton for the illustrations and to Miss Tina Chisnall for secretarial assistance.

\section{References}

${ }^{1}$ Bosman FT, Lindeman J, Kuiper G, van der Wal A, Kreunig J. The influence of fixation on immunoperoxidase staining of plasma cells in paraffin sections of intestinal biopsy specimens. Histochemistry 1977; 53:57-62.

2 Taylor CR, Burns J. The demonstration of plasma cells and other immunoglobulin-containing cells in formalin-fixed paraffin-embedded tissues using peroxidase-labelled antibody. J Clin Pathol 1974;27: 14-20. 
${ }^{3}$ Skinner JM, Whitehead R. The plasma cells in inflammatory disease of the colon: A quantitative study. $J$ Clin Pathol 1974;27:643-6.

* Dunnill MS. Quantitative methods in histology. In: Dyke SC, ed. Recent Advances in Clinical Pathology. Series V. London: Churchill, 1968:401-16.

${ }^{5}$ Brandtzaeg P, Baklien K. Immunohistochemical studies of the formation and epithelial transport of immunoglobulins in normal and diseased human intestinal mucosa. Scand J Gastroent 1976;11 Suppl 36:1-45.

${ }^{6}$ Skinner JM, Whitehead R. Morphological methods in the study of the gut immune system in man. J Clin Pathol 1976;29:564-7.

7 Willoughby CP, Piris J, Truelove SC. Tissue eosinophils in ulcerative colitis. Scand J Gastroent 1979;14:395-9.

Requests for reprints to: Dr J Piris, Department of Pathology, John Radcliffe Hospital, Oxford, UK.

\section{Reports and Bulletins prepared by the Association of Clinical Biochemists}

The following reports and bulletins are published by the Association of Clinical Biochemists. They may be obtained from The Publishing Department, British Medical Journal (ACB Technical Bulletins), BMA House, Tavistock Square, London WC1H 9JR. Overseas readers should remit by British Postal or Money Order.

SCIENTIFIC REVIEWS (price $£ 1 \cdot 00 / \$ 2.00$ each)

1 The assessment of thyroid function March 1971 FV FLYNN and JR HOBBS

2 Renal function tests suitable for clinical practice January 1972 FL MITCHELL, N VEALL, and RWE WATTS

3 Biochemical tests for the assessment of fetoplacental function May 1975 CE WILDE and RE OAKEY

4 Test of exocrine pancreatic function March 1977 AH GOWENLOCK

5 Assay of cholinesterase in clinical chemistry March 1979 ELSIE SILK, J KING, and MARY WHITTAKER

TECHNICAL BULLETINS (price $£ 1 \cdot 00 / \$ 2.00$ each)

22 Bilirubin standards and the determination of bilirubin by manual and technicon AutoAnalyzer methods January 1971 BARBARA BILLING, RUTH HASLAM, and N WALD

23 Interchangeable cells for spectrophotometers and fluorimeters September 1971 ss BROWN and AH GOWENLOCK

24 Simple tests to detect poisons March 1972 BW MEADE et al.

\section{Blood gas analysers May 1972 K DIXON}

26 Kits for enzyme activity determination September 1972 SB ROSALKI and D TARLOW

27 Assessment of pumps suitable for incorporation into existing continuous flow analytical systems November 1972 A FLECK et al.

28 Routine clinical measurements of transferrin in human serum September 1973 K DIXON
29 Control materials for clinical biochemistry (5th edition) September 1973 JF STEVENS

30 Notes on the quality of performance of serum cholesterol assays September 1973 ss BROWN

31 Determination of uric acid in blood and in urine July 1974 RWE WATTS

32 A survey of amino acid analysers readily available in the United Kingdom September 1974 JE CARLYLE and P PURKISS

33 Definitions of some words and terms used in automated analysis November 1974 A FLECK, R ROBINSON, SS BROWN, and JR HOBBS

34 Measurement of albumin in the sera of patients January 1975 LINDA SLATER, PM CARTER, and JR HOBBS

35 Investigation of the validity of temperature correction factors for serum aspartate and alanine transaminases March 1975 SB ROSALKI et al.

36 Factors influencing the assay of creatinine November 1975 JGH COOK

37 A survey of enzyme reaction rate analysers readily available in the United Kingdom July 1977 RA SAUNDERS and RF BURNS

38 Transport of specimens for clinical chemistry analysis November 1977 P WILDING, JF ZILVA, and CE WILDE

39 A scheme for the evaluation of diagnostic kits May 1978 PH LLOYD

40 A practical guide to gamma-counting in radioimmunoassay January 1980 CE WILDE and D OTTEWELL 